\title{
ANATOMIA DA MADEIRA DE TRÊS LAURÁCEAS DA FLORESTA ESTACIONAL DE MISIONES, ARGENTINA
}

Graciela Inês Bolzon de Muñiz

Departamento de Engenharia e Tecnologia Rurais - CCA

UFPR - Curitiba, PR

José Newton Cardoso Marchiori

Departamento de Ciências Florestais - CCR

UFSM - Santa Maria, RS

\section{RESUMO}

São descritas as madeiras de Nectandra lanceolata Nees et Mart. ex Nees, Nectandra saligna Nees et Mart. ex Nees e Ocotea puberula Nees, em seus aspectos gerais e microscópicos. As três espécies assemelham-se quanto aos caracteres mais importantes, referidos na literatura para a família Lauraceae. Nectandra lanceolata distingue-se facilmente pela ausência de cristais no tecido lenhoso, enquanto Nectandra saligna separa-se de Ocotea puberula pela abundância de cristais nos raios e pela presença de células oleíferas nos parênquimas axial e radial.

Palavras Chave: Anatomia da Madeira, Lauraceae, Nectandra lanceolata,

Nectandra saligna, Ocotea puberula. 


\section{SUMMARY}

The wood anatomy of Nectandra lanceolata Nees et Mart. ex Nees, Nectandra saligna Nees et Mart. ex Nees and Ocotea puberula Nees are studied in their general and microscopic features. The three species share the most important anatomical features, described in the literature for the Lauraceae family. Nectandra lanceolata may be easily set apart from the other two species by the absence of crystals in its wood. Nectandra saligna, on the other hand, distinguishes itself from Ocotea puberula by the abundance of crystals in the ray structure and by the presence of oil cells, both in axial and ray parenchyma.

Keywords: Wood Anatomy, Lauraceae, Nectandra lanceolata, Nectandra saligna, Ocotea puberula.

\section{INTRODUÇÃO}

A família Lauraceae Lindley compreende 47 gêneros e cerca de 2.500 espécies de árvores e arbustos, concentrados nas regiões tropicais e subtropicais do mundo. Na flora brasileira percebe-se uma nítida redução das Lauráceas com o aumento da latitude, pois dos 19 gêneros e 390 espécies encontradas no país, apenas 9 gêneros e 29 espécies são nativas no Rio Grande do Sul (PEDRALLI, 1982), destacando-se as três descritas no presente trabalho.

Nectandra lanceolata Nees et Mart. ex Nees é uma árvore de porte médio a grande, não raro com mais de $20 \mathrm{~m}$ de altura e $60 \mathrm{~cm}$ de D.A.P. Conhecida na Argentina como laurel amarillo, laurel canela, canela Ioro ou ayuí-saiyú, participa tanto na composição da Selva Misionera como das florestas com Araucaria angustifolia. No Brasil, sua área de ocorrência estende-se de Mato Grosso do Sul, Goiás, Minas Gerais e Rio de Janeiro até o Rio Grande do Sul. É adequada para cultivo em espaços abertos e produz frutos utilizados pela avifauna, aspectos que a recomendam para 
reflorestamentos mistos de áreas degradadas ou de preservação permanente (TORTORELLI, 1956). A madeira indica-se para chapas, compensados ornamentais, construção civil, esquadrias e forros.

Nectandra saligna Nees et Mart. ex Nees constitui um dos elementos arbóreos mais freqüentes na Selva Misionera argentina, em altitudes de 200 a $800 \mathrm{~m}$. Conhecida localmente por laurel negro, ayui-hú ou laurel-hú (TORTORELLI, 1956), recebe no Brasil os nomes de louro-negro, louro-canela, louro-amarelo, canela e canela-preta (PEDRALLI, 1982). Fornece madeira de boas propriedades tecnológicas mas de cheiro desagradável quando verde ou em contato com umidade, indicada para chapas, compensados e revestimento interior de móveis.

Ocotea puberula Nees apresenta uma dispersão mais vasta na América do Sul, encontrando-se desde a Colômbia, Venezuela e Guianas, até o sul do Brasil. Na Argentina, habita tanto a Selva Tucumano-Oranense como a Selva Misionera, onde chega a ser uma das espécies mais abundantes e características. Os troncos, de 40 a $60 \mathrm{~cm}$ de diâmetro, fornecem madeira leve $\left(0,45 \mathrm{~g} / \mathrm{cm}^{3}\right)$, de grã direita até irregular, difícil de aplainar ou lixar e de baixa resistência mecânica, indicada para a construção civil leve, obras internas, marcenaria, móveis simples ou caixotaria. Como espécie pioneira e produtora de frutos apreciados pela avifauna, recomendase para plantios mistos de áreas degradadas ou de preservação permanente (LORENZI, 1992).

A madeira das Lauráceas distingue-se por uma notável uniformidade anatômica, que impede a nítida separação de seus gêneros (METCALFE \& CHALK, 1972). Dentre os caracteres mais importantes, salientam-se os vasos com placas de perfuração simples, desprovidos de espessamentos espiralados mas freqüentemente com abundantes tiloses (gêneros Aniba, Licaria, Ocotea), as pontoações intervasculares alternas, geralmente grandes e arredondadas, e a presença de raios 2-3-seriados, distintamente heterogêneos ou quase homogêneos, com abundantes células 
oleíferas e pequenos cristais. As pontoações raio-vasculares, tipicamente grandes ou muito grandes, são arredondadas ou escalariforme-elípticas; o parênquima paratraqueal, de células grandes e freqüentemente oleíferas, varia de escasso a abundante e as fibras, geralmente septadas, exibem pontoações simples ou aréolas vestigiais (RECORD \& HESS, 1949).

Para a madeira de Nectandra lanceolata, TORTORELLI (1956) registrou anéis de crescimento distintos, marcados por fibras estreitas no lenho tardio, poros de moderadamente pequenos a medianos (27-95-190 $\mu \mathrm{m})$, em número de 7 a 20 por $\mathrm{mm}^{2}$, elementos vasculares de 250-450-750 $\mu \mathrm{m}$, com placas de perfuração simples, parênquima vasicêntrico incompleto, com 2 a 4 células por série, e raios heterogêneos II B de Kribs, com 2, 3, raramente 4 células de largura. Destacam-se, igualmente, a ausência de tiloses e cristais, além de uma menor freqüência de células oleíferas, em comparação com a madeira de Nectandra saligna.

Para Nectandra saligna foram descritos anéis de crescimento pouco demarcados, poros medianos (40-120-200 $\mu \mathrm{m})$, muito numerosos a extremamente numerosos $\left(15-50 / \mathrm{mm}^{2}\right)$, elementos vasculares de 200 a 700 $\mu \mathrm{m}$ de comprimento, freqüentemente com longos apêndices, placas geralmente simples, menos comumente escalariformes, raios heterogêneos II B de Kribs, em sua maioria bisseriados, com poucos trisseriados e raros unisseriados, parênquima paratraqueal incompleto ou curtamente aliforme e fibras septadas, com $950 \mu \mathrm{m}$ de comprimento médio, providas de pontoações simples. Foram também observadas tiloses em alguns vasos, além de cristais aciculares e células oleíferas nos raios, raramente no parênquima axial (TORTORELLI, 1956).

Para Ocotea puberula foram referidos anéis de crescimento pouco demarcados, vasos de diâmetro médio (60-120-150 $\mu \mathrm{m})$, pouco numerosos a extremamente numerosos $\left(4-50 / \mathrm{mm}^{2}\right)$, com placas de perfuração simples e escassas tiloses. Os raios, predominantemente trisseriados, contém raras células oleíferas; o parênquima axial, do tipo 
paratraqueal escasso, compreende séries de 2 a 4 células e as fibras, libriformes e septadas, medem 840-1080-1230 $\mu \mathrm{m}$ de altura (TORTORELLI, 1956).

O presente trabalho visa a descrição microscópica destas três espécies, com base em amostras procedentes de Misiones - Argentina e uma análise taxonômico-filogenética das estruturas observadas.

\section{MATERIAIS E MÉTODOS}

O material estudado consiste de 3 amostras de madeira, para cada espécie, provenientes de uma floresta da Universidad Nacional de Misiones, localizada no Departamento de Guaraní (Argentina). As amostras foram extraídas de discos tomados a 1,30 $\mathrm{m}$ do solo e preferencialmente em região de alburno. O material lenhoso e respectivas exsicatas de material botânico encontram-se arquivadas no Laboratório de Dendrologia da Facultad de Ciencias Forestales, da Universidad Nacional de Misiones.

Os corpos de prova para estudos anatômicos foram orientados para a obtenção de cortes nos planos transversal, longitudinal radial e longitudinal tangencial. Após o amolecimento, por fervura em água, procedeu-se ao seccionamento dos mesmos, em micrótomo de deslizamento (modelo Spencer AO no 860), com espessura nominal de corte variando de 14 a $24 \mu \mathrm{m}$. Usou-se coloração com vermelho-de-acridina, crisoidina e azulde-astra (DUJARDIN, 1964), desidratação em série alcoólica e montagem permanente, com "Entellan".

Para a maceração dos tecidos seguiu-se o método de Jeffrey (FREUND, 1970), usando-se coloração por safranina e o mesmo meio de montagem anteriormente referido.

Os dados quantitativos dos caracteres anatômicos foram processados diretamente no aparelho analisador de imagens "Videoplan", acoplado a um computador, obtendo-se desta forma os respectivos valores 
mínimos, médios, máximos e desvio padrão (s), com o uso de programas aplicativos.

As descrições macroscópicas seguiram a norma COPANT (1973). Para as descrições microscópicas e mensurações de elementos celulares individuais seguiu-se a ABNT, com as alterações introduzidas por MUÑIZ ( 1986).

As fotomicrografias de detalhes anatômicos foram tomadas em aparelho Carl Zeiss; usou-se filme Kodak-Panatomic X, ASA 32 e ampliações em papel fotográfico Kodabromid F-3 brilhante.

\section{DESCRIÇÃO DAS MADEIRAS}

\section{Nectandra lanceolata Nees et Mart. ex Nees}

Caracteres gerais: Madeira de cerne e alburno indistintos, de cor amarela, uniforme. Figura suavemente demarcada pela disposição dos poros e da grã. Grã freqüentemente revessa e ondulada, listrada nas faces radiais. Madeira leve $\left(0,45\right.$ a $\left.0,50 \mathrm{~g} / \mathrm{cm}^{3}\right)$, de cheiro pouco pronunciado e de textura média, heterogênea.

Anéis de crescimento: Demarcados pelo espessamento da parede e redução no diâmetro radial de fibras do lenho tardio (Figura 1 A,B).

Vasos: Em porosidade difusa e com freqüência de 6 a 24 poros por $\mathrm{mm}^{2}$. Vasos predominantemente múltiplos e solitários (Figura $1 \mathrm{~A}$ ), de forma oval a circular (Figura $1 \mathrm{~A}, \mathrm{~B}$ ); os múltiplos são geminados, radiais (até 7 poros) ou mais raramente racemiformes (até 5 poros). Com lume de 25 - 90 - $190 \mu \mathrm{m}$ de diâmetro tangencial ( $s=19,69$ ), apresentam parede com $3-6-12 \mu \mathrm{m}$ de espessura e freqüentes tilos (Figura 1.B). Linhas vasculares retilíneas ou levemente sinuosas (Figura 1 D). Elementos vasculares de $200-465-760 \mu \mathrm{m}(\mathrm{s}=21,78)$ de comprimento, com apêndices presentes em uma ou em ambas extemidades. Placas de perfuração geralmente simples, com raras placas escalariformes oblíquas, 
em vasos de menor diâmetro. Pontoações intervasculares de 3 - 7 - $12 \mu \mathrm{m}$ de diâmetro, alternas, ornamentadas ou não, de forma oval, circulares ou freqüentemente poligonais, devido à proximidade das mesmas, e com abertura lenticular inclusa (Figura $2 \mathrm{C}$ ). Pontoações raio-vasculares e parênquimo-vasculares, pequenas a grandes $(6-14-20 \mu \mathrm{m})$, irregulares, em disposição escalariforme e com delicadas incrustações de aspecto granulado na membrana de fundo (Figura 2 B).

Parênquima axial: Vasicêntrico, escasso a moderadamente abundante. De tipo seriado, reúne de 2 a 4 células por série (Figura 2 B), medindo $206-259-400 \mu \mathrm{m}$ de altura $(\mathrm{s}=24,08)$ por $13-23-32 \mu \mathrm{m}$ de diâmetro. Células cristalíferas, não observadas; células oleíferas, muito escassas.

Raios: Heterogêneos (Figura $1 \mathrm{C}$ ) e com freqüência de 5 a 8 por $\mathrm{mm}$, constituídos principamente de células procumbentes e 1 ou 2 fileiras marginais de células quadradas e eretas; apresentam escassas células envolventes e raras células oleíferas. Raios unisseriados, pouco freqüentes e com 1 - 6 - 17 células de altura. Raios multisseriados, em sua maioria bi e trisseriados, mais raramente com 4 ou 5 células de largura (20 - 35 - $60 \mu \mathrm{m}$ ), por $100-357-500 \mu \mathrm{m}(\mathrm{s}=41,89)$ e até 45 células de altura.

Fibras: Libriformes e septadas (Figura 2 A), com minúsculas pontoações simples de seção poligonal ou arredondada. Medem 600 - 1000 $1540 \mu \mathrm{m} \quad(\mathrm{s}=112,34)$ de comprimento, por $10-16-30 \mu \mathrm{m}$ de diâmetro externo $(s=2,59)$, com lúmen de 2,5 - 9,6 - $15 \mu \mathrm{m}(s=1,98)$ de diâmetro.

\section{Nectandra saligna Nees et Mart. ex Nees}

Caracteres gerais: Madeira de cerne e alburno distintos, com alburno amarelo-ocráceo e cerne pardo, levemente rosado, com manchas irregulares mais escuras. Macia e leve $\left(0,52 \mathrm{~g} / \mathrm{cm}^{3}\right)$, apresenta textura fina heterogênea, grã irregular, cheiro desagradável quando umedecida, brilho 
suave e figura marcada pela variação de cor entre os lenhos inicial e tardio, por vezes espigada.

Anéis de crescimento: Pouco distintos, evidenciados pela maior espessura da parede e o achatamento das fibras no lenho tardio (Figura $3 \mathrm{~A}, \mathrm{~B}$ ).

Vasos: Porosidade difusa, com freqüência de 10 a 40 poros por $\mathrm{mm}^{2}$. Poros solitários, de seção oval ou circular (Figura $3 \mathrm{~A}, \mathrm{~B}$ ), em múltiplos radiais (2 a 6 poros) e racemiformes (até 5 poros), freqüentemente com tilos; possuem lúmen de $30-100-210 \mu \mathrm{m}(s=21,54)$ de diâmetro tangencial e parede de 1,5-5-8 $8 \mathrm{~m}$ de espessura (Figura $3 \mathrm{~A}, \mathrm{~B}$ ). Linhas vasculares retilíneas. Elementos vasculares de $200-509-700 \mu \mathrm{m}$ (s = 49,76 ) de comprimento, com apêndices longos, em uma ou em ambas extremidades. Placas de perfuração predominantemente simples, por vezes escalariformes e oblíquas (1 a 5 barras) nos vasos de menor diâmetro (Figura 4 D). Pontoações intervasculares alternas, medianas (5 - 8 - $12 \mu \mathrm{m}) \mathrm{e}$ circulares; possuem aberturas exclusas em estreita fenda, coalescentes e ornamentadas. Pontoações raio-vasculares e parênquimo-vasculares (Figura 4 B) arredondadas ou transversalmente alongadas, em arranjo escalariforme e por vezes unilateralmente compostas.

Parênquima axial: Moderadamente abundante, dos tipos paratraqueal vasicêntrico e aliforme-confluente, em curtas faixas oblíquas interrompidas; parênquima apotraqueal difuso também presente, por vezes com células oleíferas. As séries medem de 350 a $950 \mu \mathrm{m}$ de altura e as células individuais de 65 a $250 \mu \mathrm{m}$ de comprimento. As células oleíferas, nitidamente fusiformes, variam de 60 a $100 \mu \mathrm{m}$ de altura por 24 a $30 \mu \mathrm{m}$ de largura.

Raios: Heterogêneos, constituídos por células procumbentes na parte central e 1 ou 2 fileiras marginais de células quadradas e eretas (Figura 3 D). São geralmente trisseriados (52 \%), menos comumente bisseriados (25\%), tetrasseriados (20\%) e unisseriados (3\%) (Figura 4 
A,B). Os unisseriados medem 130 a $250 \mu \mathrm{m}$ de altura; os multisseriados variam de 40 - 320 - $720 \mu \mathrm{m}$ de altura, com $10-33-67 \mu \mathrm{m}$ de largura. Raios verticalmente fusionados, ocasionais. Cristais aciculares, prismáticos, fusiformes, estilóides e tabletóides, freqüentes em células radiais (Figura 3 D). Células oleíferas, freqüentes nas margens (Figuras $3 \mathrm{D}, 4 \mathrm{~A}, \mathrm{~B}$ ).

Fibras: Libriformes e septadas (Figura 4 A,B), por vezes gelatinosas, principalmente no lenho incial. Variam de $640-1000-1350 \mu \mathrm{m}$ de comprimento, por 12,5 a $27,7 \mu \mathrm{m}$ de diâmetro externo e 5 a $20 \mu \mathrm{m}$ de diâmetro no lúmen, contendo ocasionalmente cristais tabletóides ou aglomerados irregulares.

\section{Ocotea puberula (Nees et Mart.) Nees}

Caracteres gerais: Madeira de cerne e alburno distintos, com alburno creme-acetinado, cerne pardo-amarelado ou castanho e figura suave, marcada por veios longitudinais mais claros, pardo-acinzentados. Com massa específica de 0,39 a $0,47 \mathrm{~g} / \mathrm{cm}^{3}$, apresenta textura média, heterogênea e grã oblíqua a revessa, freqüentemente com suave espigado.

Anéis de crescimento: Individualizados por zonas fibrosas tangenciais mais escuras.

Vasos: Em porosidade difusa, uniforme, com freqüência de 4 11 - 18 poros $/ \mathrm{mm}^{2}$. Principalmente solitários, apresentam-se também em curtos múltiplos radiais (de 1 a 5 ) e em múltiplos racemiformes de até 8 poros (Figura 5 A,B). Elementos vasculares de $100-148-210 \mu \mathrm{m}$ de diâmetro tangencial ( $\mathrm{s}=26,78$ ) e $400-594-860 \mu \mathrm{m}$ de comprimento ( $\mathrm{s}=$ 45,91), com apêndices de 40 - $105-300 \mu \mathrm{m}$, presentes em ambas extremidades. Placas de perfuração geralmente simples e oblíquas, por vezes escalariformes ou irregular-reticuladas, nos vasos de menor diâmetro (Figura 6 D). Pontoações intervasculares alternas (Figura 6 A), arredondadas, grandes (10 - 11,5 - $14 \mu \mathrm{m})$, de forma circular ou poligonal e 
com abertura lenticular, horizontal. Pontoações parênquimo-vasculares semiareoladas, de $10-14-18 \mu \mathrm{m}$ de diâmetro $(\mathrm{s}=2,01)$, ovais ou horizontalmente estendidas e com incrustações em toda a membrana de fundo. Pontoações raio-vasculares semelhantes às parênquimo-vasculares: grandes e com incrustações. Tilos presentes, numerosos (Figura 5 A,B).

Parênquima axial: Paratraqueal, escasso até vasicêntrico, com 2 a 4 células por série e 50 - 113 - $177 \mu \mathrm{m}$ de altura $(s=16,34)$ por 22 - 32 $50 \mu \mathrm{m}$ de diâmetro.

Raios: Heterogêneos, com freqüência de $3-5-7$ raios $/ \mathrm{mm}$. Predominam os trisseriados (50\%), menos comumente bisseriados (28\%), tetrasseriados (20\%) e unisseriados (2\%). Os unisseriados, compõem-se de células eretas e quadradas. Os multisseriados, reúnem células procumbentes, na parte central, e margens unisseriadas mais baixas, compostas de células eretas e quadradas, ou então com uma única fileira de células eretas; medem 400 - 570 - $800 \mu \mathrm{m}$ de altura $(s=27,65)$, com 4 - 12 40 células, e 27 - $40-50 \mu \mathrm{m}$ de largura, apresentando raros fusionamentos axiais. Células oleíferas escassas, dispostas na margem ou no centro dos raios. Cristais prismáticos e estilóides, escassos no tecido radial (Figura 5 D).

Fibras: Libriformes, septadas (Figuras 5 C; 6 B,C,D), ligeiramente gelatinosas em algumas zonas (Figura $5 \mathrm{~A}$ ) e com minúsculas pontoações simples nas paredes. Medem 840 - 1193 - $1550 \mu \mathrm{m}$ de comprimento $(s=113,42)$, por 12,5 - 22 - $37 \mu \mathrm{m}$ de diâmetro, com parede de 1,2 - 4 - $9 \mu \mathrm{m}$ de espessura. Cristais prismáticos, solitários ou aglomerados, de ocorrência ocasional no tecido fibroso (Figura 6 C).

\section{DISCUSSÃO}

Os caracteres anatômicos mais importantes no material em estudo coincidem com o referido por METCALFE \& CHALK (1972) e RECORD \& HESS (1949) para as Lauráceas: elementos vasculares de 
comprimento médio, placas de perfuração predominantemente simples, pontoações intervasculares grandes e alternas, parênquima paratraqueal, raios heterogêneos e fibras libriformes septadas.

Embora menos freqüentes e restritas aos elementos vasculares de menor diâmetro, foram observadas placas de perfuração escalariformes nas três espécies em estudo, caráter referido por METCALFE \& CHALK (1972) como bastante comum na subfamília Persoideae.

A presença de células oleíferas nos parênquimas axial e radial de Nectandra lanceolata, Nectandra saligna e Ocotea puberula é citada na literatura para as Magnoliales, ordem considerada por TAKHTAJAN (1969) como a provável ancestral das Laurales.

As três espécies em estudo não podem ser identificadas com base em caracteres quantitativos de vasos, parênquima axial, raios e fibras. Esta relativa homogeneidade estrutural, que impede até mesmo a separação anatômica dos gêneros Nectandra e Ocotea, foi apontada por METCALFE \& CHALK (1972) como um aspecto relevante na anatomia das Lauráceas. A identificação destas espécies pode ser realizada com base na forma, abundância e localização de cristais e células oleíferas.

Nectandra lanceolata separa-se facilmente das outras duas espécies pela ausência de cristais no tecido lenhoso. Nectandra saligna distingue-se de Ocotea puberula pela abundância de cristais fusiformes, aciculares, prismáticos e tabletóides no tecido radial, bem como de células oleíferas nos parênquimas axial e radial. Em Ocotea puberula, ao contrário, são escassos os cristais no tecido radial e poucas as células oleíferas, limitadas neste caso às margens e parte central dos raios.

Os dados quantitativos de elementos vasculares, parênquima axial, raios e fibras, observados no material em estudo, aproximam-se dos referidos por TORTORELLI (1956) para as mesmas espécies. 
A estrutura anatômica conjuga caracteres primitivos, como raios heterogêneos, com outros tidos como evoluídos, tais como parênquima paratraqueal e fibras de pontoações simples. Apesar da predominância de placas de perfuração simples, a ocorrência de algumas placas escalariformes, bem como de células oleíferas e de pontoações raiovasculares transversalmente alongadas, sugerem uma relativa proximidade filogenética destas lauráceas com as Magnoliales e a família Monimiaceae, posicionadas por TAKHTAJAN (1969) e CRONQUIST (1981), no início de seus conhecidos sistemas de classificação vegetal.

\section{CONCLUSÕES}

A análise anatômica das três espécies de Lauráceas descritas no presente trabalho indica as seguintes conclusões:

- As três espécies apresentam elementos vasculares de comprimento médio, pontoações intervasculares grandes e alternas, parênquima paratraqueal, raios heterogêneos e fibras septadas, concordando com o descrito na literatura para a família Lauraceae.

- Apesar da predominância de placas de perfuração simples, foram observadas placas escalariformes nos elementos vasculares de menor diâmetro, para as três espécies.

- Nectandra lanceolata distingue-se pela ausência de cristais no tecido lenhoso.

-Nectandra saligna separa-se de Ocotea puberula pela abundância de cristais nos raios e pela presença de células oleíferas nos parênquimas axial e radial. 
- A anatomia da madeira mostra que as três espécies reunem caracteres primitivos e evoluídos.

- A estrutura anatômica corrobora a proximidade filogenética das Lauraceae com as Monimiaceae e Magnoliales.

\section{REFERÊNCIAS BIBLIOGRÁFICAS}

COPANT - COMISSÃO PANAMERICANA DE NORMAS TÉCNICAS. Descrição macroscópica, microscópica e geral da madeira esquema I de recomendação. Colômbia, 1973. 19 p. (COPANT 30).

CRONQUIST, A. An integrated System of Classification of Flowering Plants. New York: Columbia University Press, 1981. 1262 p.

DUJARDIN, E.P. Eine neue Holz-zellulosenfaerbung. Mikrokosmos, n. 53, p. 94, 1964.

FREUND, H. Handbuch der Mikroskopie in der Technik. Frankfurt: Umscham Verlag, 1970. 375 p.

LORENZI, H. Árvores Brasileiras - Manual de identificação e cultivo de plantas arbóreas nativas do Brasil. Nova Odessa:Editora Plantarum, 1992. $352 \mathrm{p}$.

METCALFE, C.R., CHALK, L. Anatomy of the Dicotyledons. Oxford: Clarendon Press, 1972. 1500 p.

MUÑIZ, G.I.B. Descrição da estrutura e ultraestrutura da madeira de cinco espécies de Prosopis da Argentina e análise da metodologia. Curitiba, Curso de Pós-Graduação em Engenharia Florestal, 1986. 192 p. Dissertação de Mestrado. 
PEDRALLI, G. A família Lauraceae Lindley no Rio Grande do Sul, Brasil. Porto Alegre, Universidade Federal do Rio Grande do Sul. Curso de Pós-Graduação em Botânica, 1982. 183 p. Dissertação de Mestrado. RECORD, S.J., HESS, R.W. Timbers of the New World. New Haven: Yale University Press, 1949. 640 p.

TAKHTAJAN, A. Flowering Plants - Origin and Dispersal. Edinburgh: Oliver \& Boyd, 1969. $310 p$.

TORTORELLI, L.A. Maderas y Bosques Argentinos. Buenos Aires: Editorial ACME, 1956. 910 p. 


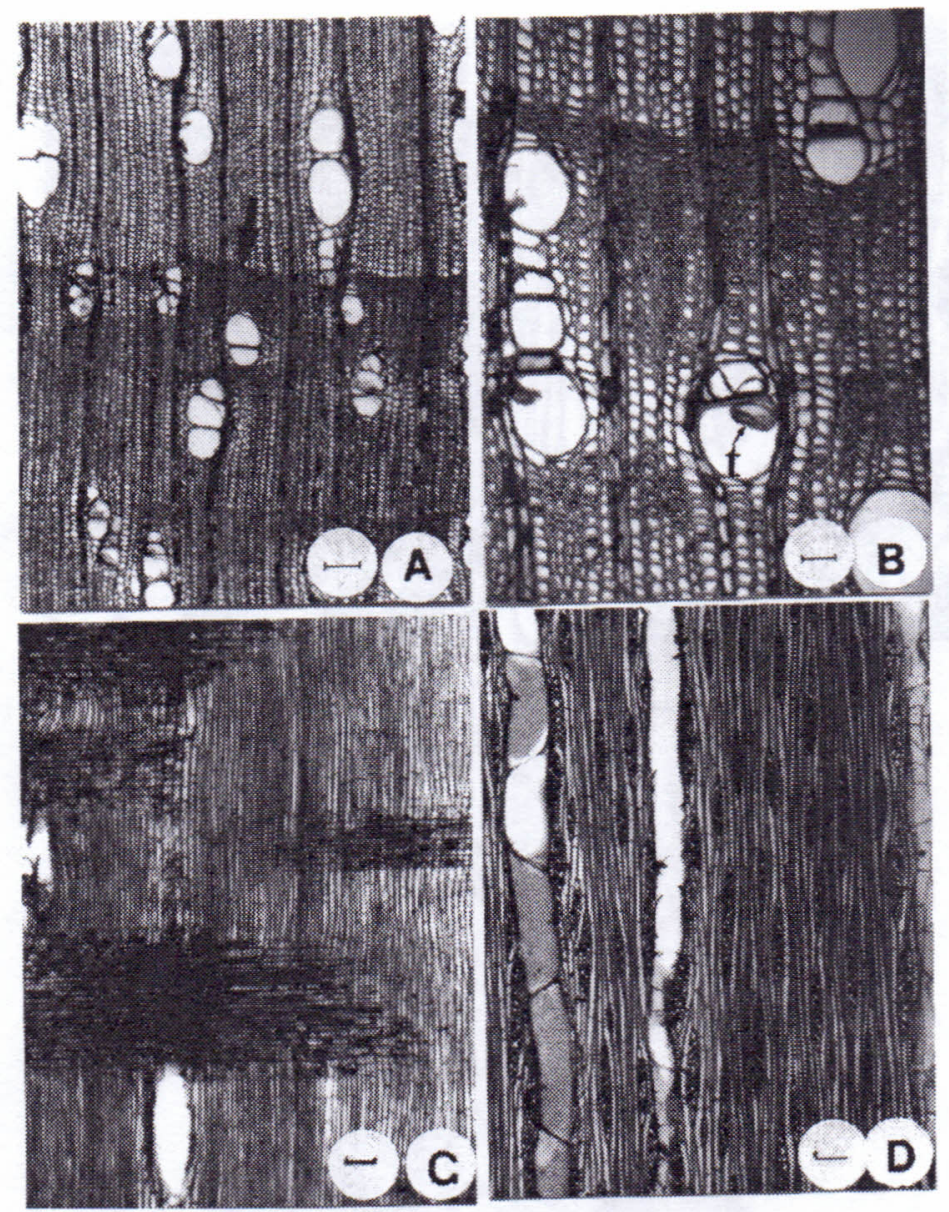

FIGURA 1. Aspectos anatômicos da madeira de Nectandra lanceolata. A. Seção transversal, mostrando um limite de anel de crescimento (seta), e poros solitários ou em múltiplos radiais (escala $=100 \mu \mathrm{m}$ ). B. Seção transversal, destacando o limite de um anel de crescimento (seta), 7 poros em agrupamento radial, parênquima vasicêntrico, libras gelatinosas e tilos $(\mathrm{t})$ nos vasos (escala $=40 \mu \mathrm{m})$. C. Tecido radial heterogêneo e fibras septadas, em seção radial (escala $=100 \mu \mathrm{m}$ ). $\mathbf{D}$. Seção tangencial, mostrando raios multisseriados, fibras septadas e elementos de vasos com pontoações intervasculares (escala $=100 \mu \mathrm{m}$ ). 

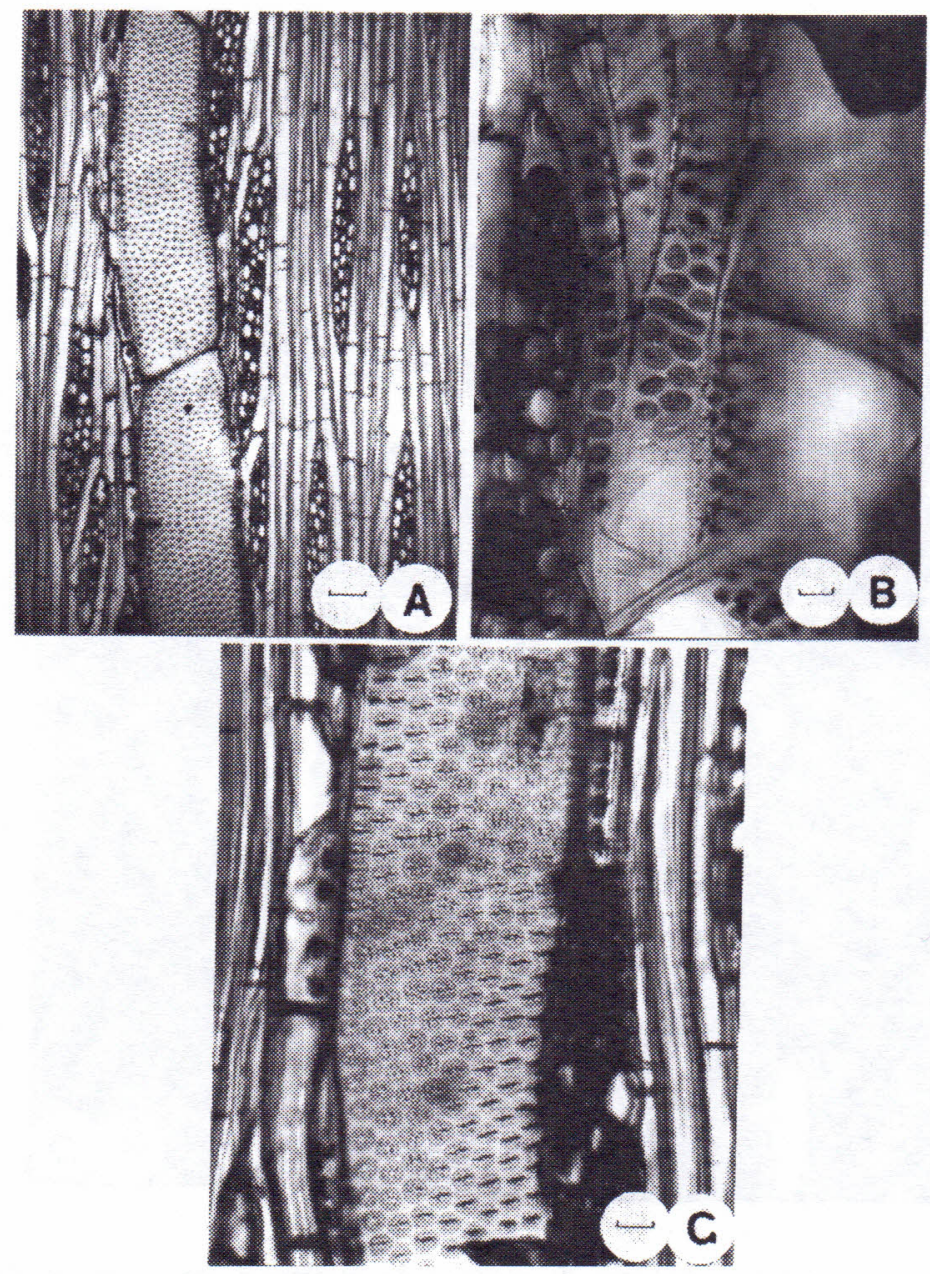

FIGURA 2. Aspectos anatômicos da madeira de Nectandra lanceolata. A. Seção tangencial, mostrando raios multisseriados, fibras septadas e elementos de vasos com pontoações intervasculares alternas (escala $=40 \mu \mathrm{m}$ ). B. Seção tangencial, mostrando pontoações parênquimo-vasculares irregulares, escalariformes, com incrustações delicadamente granuladas na membrana de fundo (escala $=12,5 \mu \mathrm{m}$ ). C. Seção tangencial, salientando um raio multisseriado, fibras septadas e elemento de vaso com pontoações intervasculares ornamentadas (escala $=12,5 \mu \mathrm{m}$ ). 

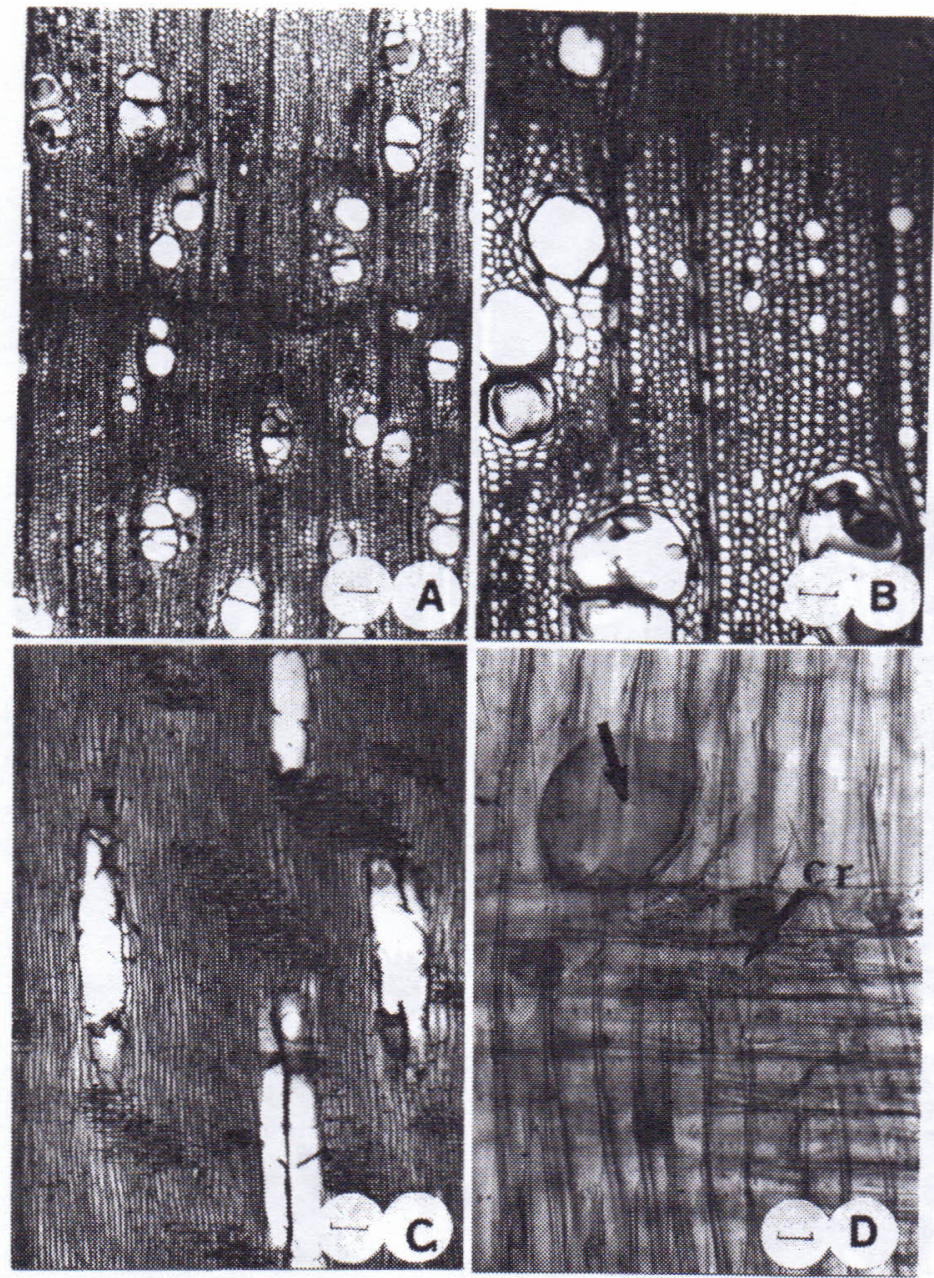

FIGURA 3. Aspectos anatômicos da madeira de Nectandra saligna. A. Seção transversal, mostrando um limite de anel de crescimento (seta), e poros solitários e em múltiplos radiais (escala $=100 \mu \mathrm{m}$ ). B. Seção transversal, destacando poros solitários e em múltiplos de 3 , abundantes células oleíferas (seta) e presença de tilos nos vasos (escala $=40 \mu \mathrm{m})$. C. Tecido radial heterogêneo e fibras septadas, em seção radial (escala $=100 \mu \mathrm{m})$. D. Seção radial, mostrando célula oleifera (seta) e abundantes cristais (cr) em células de raio (escala $=12,5 \mu \mathrm{m})$.

Rev. Ciência e Natura, Santa Maria, 21: $77 \quad$ - $96 \quad, 1999$. 


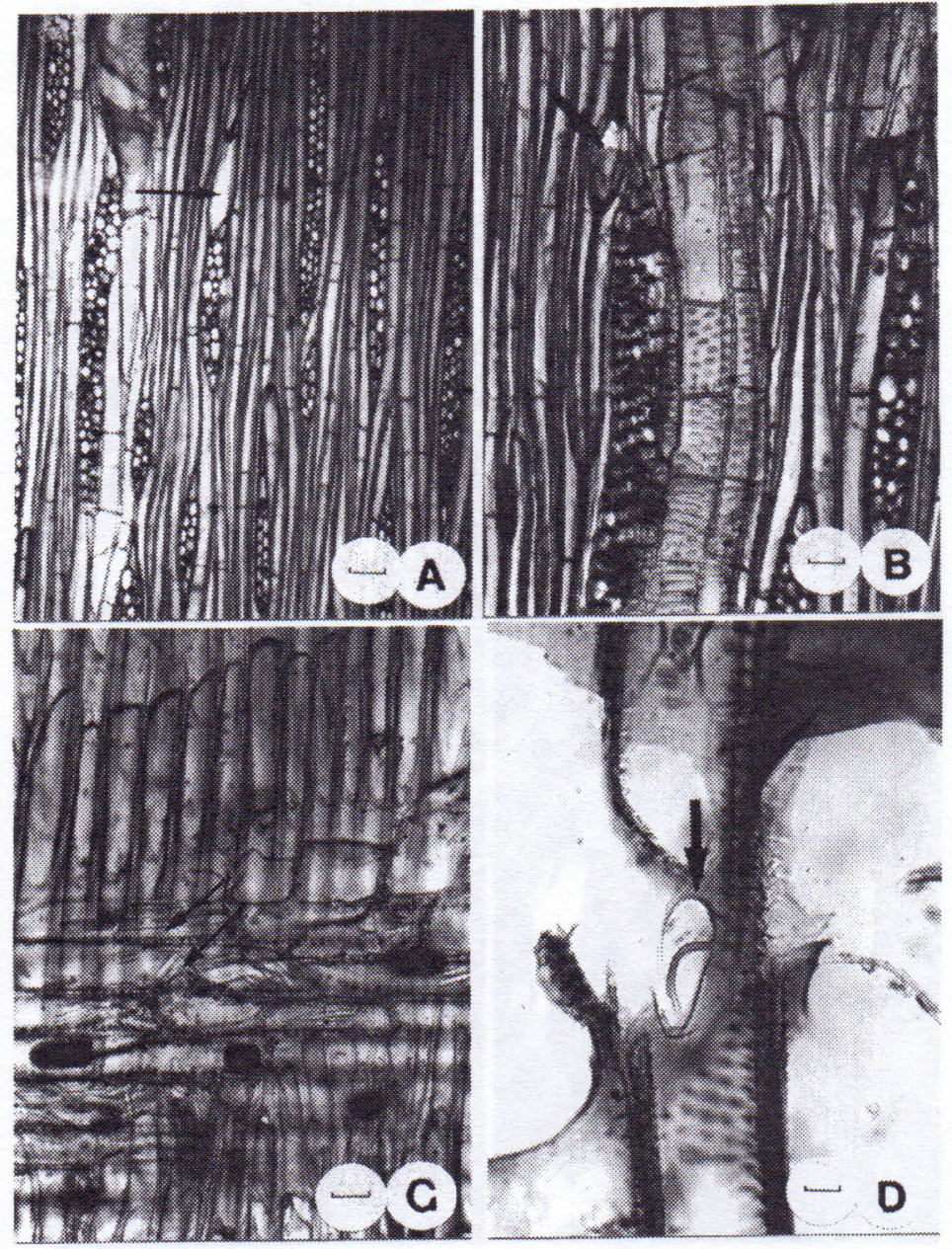

FIGURA 4. Aspectos anatômicos da madeira de Nectandra saligna. A. Seção tangencial, mostrando raios multisseriados heterogêneos, uma célula oleífera marginal (seta) e fibras septadas (escala $=40 \mu \mathrm{m}$ ). B. Seção tangencial, destacando pontoações parênquimo-vasculares com incrustações delicadamente granuladas na membrana do fundo, célula oleífera (seta), parênquima seriado e fibras septadas (escala $=25 \mu \mathrm{m}$ ). C. Cristais aciculares (seta), em células de parênquima radial (escala = 12,5 $\mu \mathrm{m})$. D. Placa de perfuração escalariforme (seta), em vaso de pequeno diâmetro (seção radial; escala $=12,5 \mu \mathrm{m}$ ). 

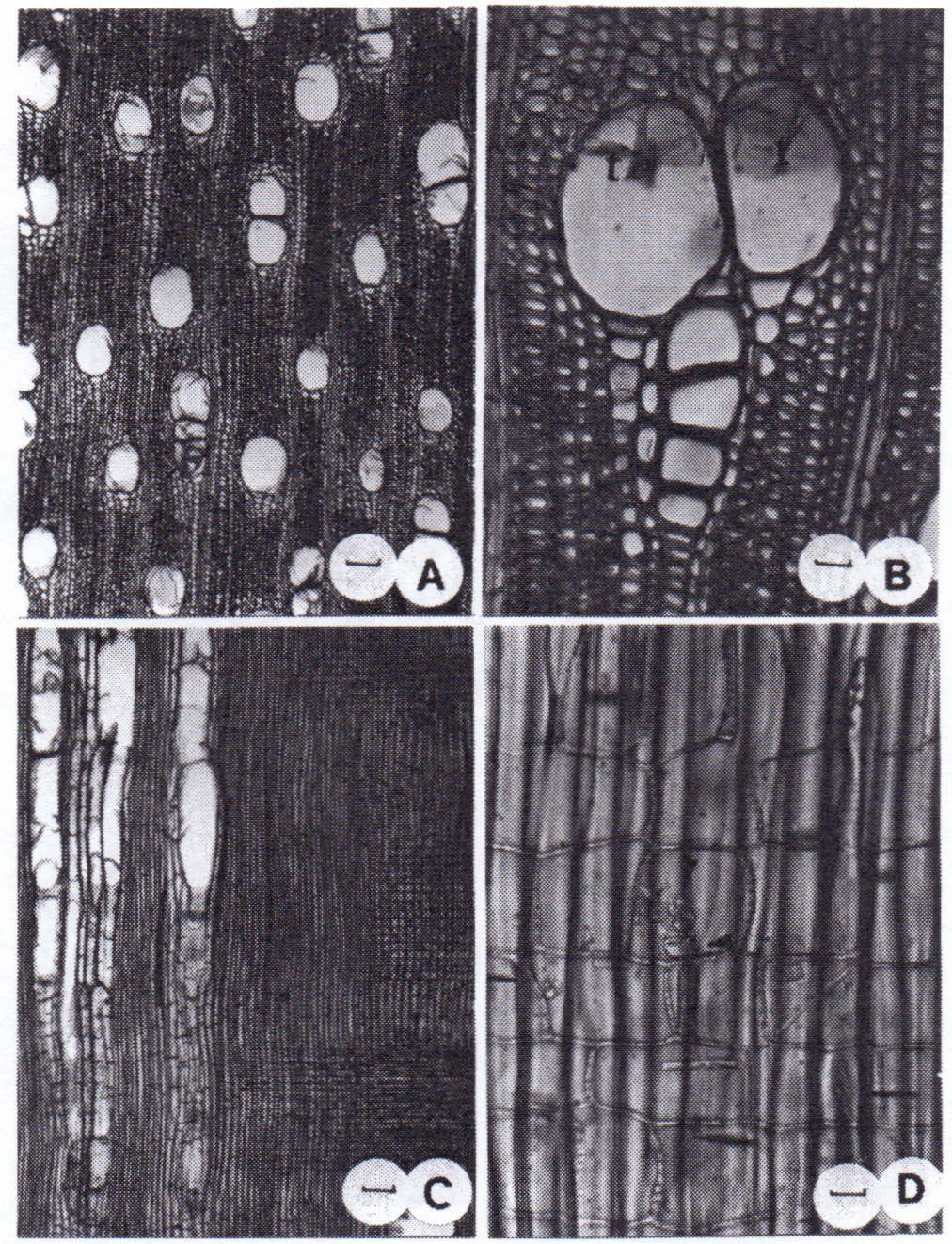

FIGURA 5. Aspectos anatômicos da madeira de Ocotea puberula. A. Seção transversal, destacando a porosidade difusa e parênquima paratraqueal (escala $=100 \mu \mathrm{m})$. B. Seção transversal, mostrando poros solitários e em múltiplo de 4 , tilos em vasos $(\mathrm{t})$ e fibras gelatinosas (escala $=25 \mu \mathrm{m}$ ). C. Tecido radial heterogêneo, elementos de vaso e fibras septadas, em seção radial $($ escala $=100 \mu \mathrm{m})$. D. Células cristalíferas em raio, contendo estilóides, cristais prismáticos e aglomerados irregulares (escala $=12,5$ $\mu \mathrm{m})$.

Rev. Ciência e Natura, Santa Maria, 21: $77 \quad-96 \quad, 1999$. 

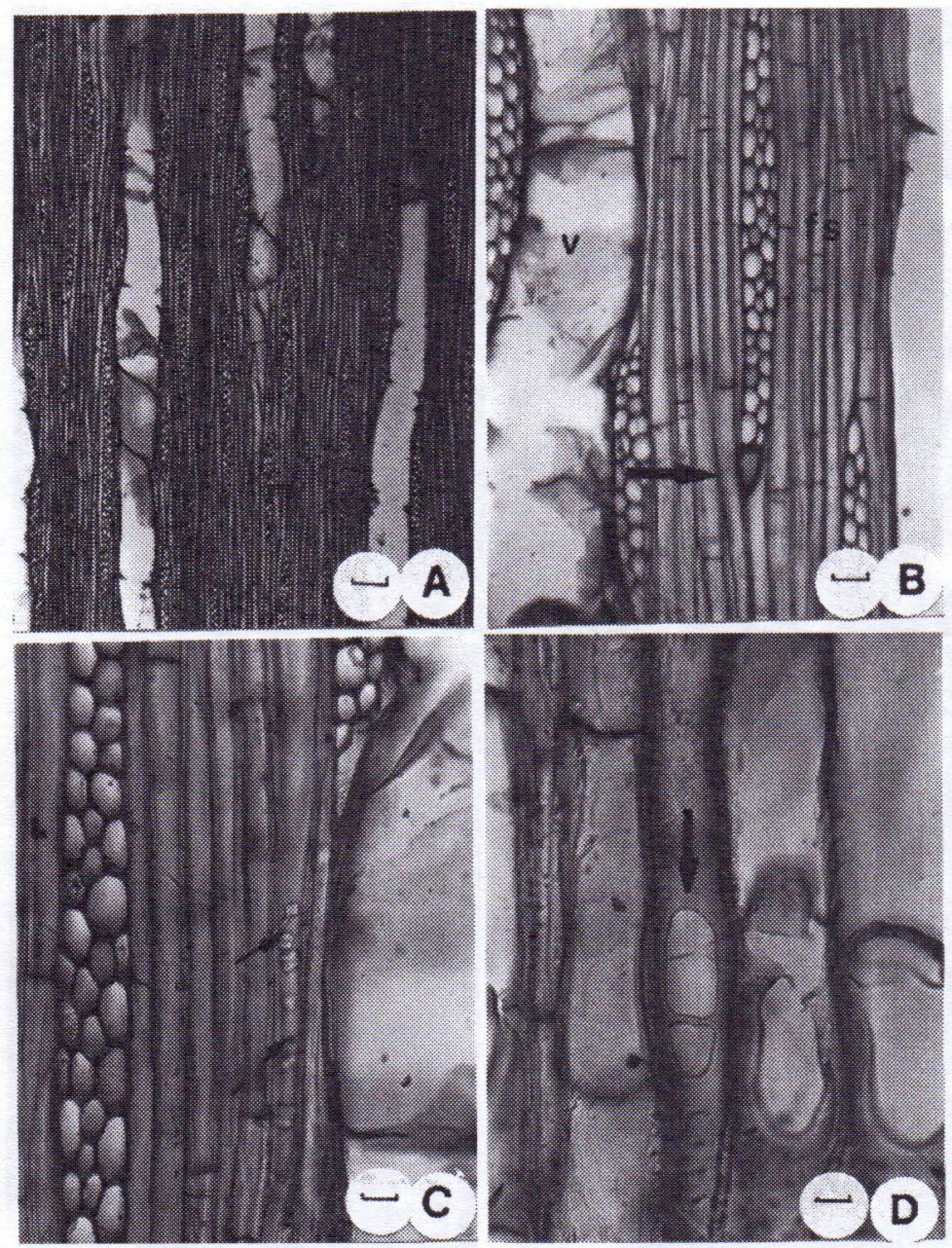

FIGURA 6. Aspectos anatômicos da madeira de Ocotea puberula. A. Seção tangencial, mostrando raios multisseriados e elementos de vaso com pontoações intervasculares (escala $=100 \mu \mathrm{m})$ B. Seção tangencial, destacando célula oleifera (seta) na margem de raio multisseriado, elementos de vaso $(\mathrm{v})$ e fibras septadas (fs) (escala $=25 \mu \mathrm{m})$. C. Seção tangencial, destacando cristais prismáticos (seta) em fibras (escala $=12,5$ $\mu \mathrm{m})$. D. Placas de perfuração simples e escalariforme (seta), em seção radial (escala $=12,5 \mu \mathrm{m})$. 